\title{
Interpersonal Factors as Correlates of Alcohol Use among Secondary School Adolescents in Oyo State, Nigeria
}

\author{
D.A.Adeyemo \\ Department of Guidance and Counselling, University of Ibadan, Ibadan, Nigeria \\ E-mail: drdaadeyemo@yahoo.com
}

KEYWORDS Interpersonal Factors. Alcohol Use. Secondary School Adolescents

\begin{abstract}
The purpose of this study was to examine the relationships between interpersonal factors and adolescents drinking. The study's participants were five hundred senior secondary school students randomly drawn from twenty secondary schools in Oyo State, Nigeria. Two validated instruments were used to collect data from the students. Multiple regression analysis was employed to determine the joint and relative contributions of the independent variables to the prediction of the dependent variable. The results indicated that the three independent variables both jointly and relatively contributed significantly to the prediction of the criterion measure. on the basis of the finding of the study, it is recommended that adolescents should be exposed to counselling intervention programmes that would enable them withstand peer, neighbourhood and parental pressures that predisposed them to alcohol consumption.
\end{abstract}

\section{INTRODUCTION}

Alcohol consumption among adolescent all over the world has assumed an alarming dimension. It has become so worrisome that it has gained prominence in social discourse. The prevalence rate of alcohol use among adolescents in different parts of the world gives room for concern. for instance in the United States of America, it was reported that $52 \%$ of the eighth graders and $80 \%$ of the high school seniors have used alcohol at sometime. $25 \%$ of the eighth graders and $62 \%$ of high school seniors have been drunk (National Youth Violence Prevention, 2000). As pointed out by Eastand (1990), there were about 5 millions habitual alcohol drunkers in France. The situation in Nigeria showed that there is high prevalence of alcohol use among adolescents and there is high probability that the frequency of alcohol drinking will continue to increase (Ogunremi and Rotimi, 1989).

The dangers associated with alcohol consumption make it a serious threat not only to the health of individual consumer but also that of the society as well. This is buttressed by the submission of Lindberg et al. (2000). According to them over $90 \%$ of the teens who drink regularly also do other things that can put them or those around them at risk for harm. Such behaviours include illegal drugs, fighting, carrying weapons and having unsafe sex. Eastang (1990) found that 6000 out of about five million habitual drinkers in France died from alcohol related diseases. According to Permanen (1991) alcohol is involved in a high percentage of various violent crimes committed by teenagers and adults. Although estimates vary, it has been established that alcohol plays a key role in many violent crimes including murder, assault, manslaughter and rape (Roizen, 1997). Evidence had also suggested that drinking leads to increased aggressiveness because it lowers inhibition, including those that would normally prevent aggressive behaviour. Alcohol also impairs judgement and may cause people to overreact to perceived threats or to fail to consider the future risk of an impulsive violent response (National Institute on Alcohol Abuse and Alcoholism, 1997).

The pertinent issue to raise therefore is what is it that is sustaining or reinforcing the use of alcohol among adolescents despite the awareness of the potential dangers it constitute to healthy living? The purpose of the present study was to look at the roles factors such as peer influence, parental and neighbourhood influences play in the consumption of alcohol among adolescents.

\section{Review of Relevant Studies}

Jessor and Jessor (1975) and Nash (1997) found out adolescents consume alcohol because they are exposed to it by their friends and peers. Similar finding was made by McPherson (1997) who confirmed that peer pressure is one of the factors that encourage students to drink alcoholic beverage. In a profile study of high school boys who drink alcohol in Alexandria, Egypt and New York, it was established by McPherson (1992) that 
peer pressure was a potent factor in adolescent alcohol use.

The compelling need to fit into and belong to a group of friends may be a motivating factor in alcohol use. Peer pressure can take the form of direct offers or even pressure to drink and it can be more subtle such as the perception 'that everyone is drinking'. Adolescents rated peer pressure as one of the top three reasons for using alcohol (Dupre et al., 1995). In a research conducted among undergraduates, Orcutt (1991) found that although students who were generally light drinkers did not increase their drinking in the presence of close friends, students disposed to drinking heavily did so among friends. Martin and Hoffman (1993) in their study of undergraduate students, found that peer influence in terms of the number of college and non-college friends who drank was a significant predictor of consumption even after controlling for individuals living environment and positive expectancies associated with alcohol use.

The desire by adolescents to gain emancipation from parental control and develop a unique individual identity predisposes them to behave in a way that helps them to be liked and respected by their peers. As Van Hecke (1995) pointed out the use of alcoholic beverages by adolescents is often seen as a way to become more adults, because they have grown up to believe this. The influence of peer factor such as peer alcohol use, peer norms and susceptibility to peer pressure have been found to account for significant variance in adolescent alcohol consumption (Schwarzer, 1996).

Parents have significant impacts on the lives of their children while some are good role models for their children, the reverse is the case in some instances. In a study conducted by Hazelden Foundation (1998) parents were found not to have given their adolescent children a strict no use message on alcohol. The research further indicated that parents only call the attention of their children to the consequential effect of their drinking behaviour on driving to the neglect of other devastating effect of alcohol. In a study done by Ethen (2000), parental influence was identified as a critical factor in adolescent drinking as a critical factor in adolescent drinking. In a finding similar to this, Jayant et al. (1991) demonstrated that the drinking consumption rate in students whose parents were drinkers $(25.3 \%)$ was significantly higher than those whose parents were non-drinkers $(13.7 \%)$
Swaim et al. (1997) confirmed that parents who are permissive about discipline and who do not enforce any rules or standard are even more likely to end up with children who drink regularly. They found in their study that some parents offered alcohol beverages to their children as reward for good behaviour. In a developmental stage analysis of alcohol use, Lowman (1982) discovered that $85 \%$ of adolescents who use alcohol had parents who drank alcohol while $72 \%$ of abstaining adolescents had parents who abstained from it. Parental approval and close association with parents who drink alcohol influence the act of alcohol consumption.

Another variable whose impact on adolescent drinking behaviour was investigated is neighbourhood influence. The term neighbourhood has been variously defined by researchers in the field. These various viewpoints notwithstanding, there seem to be little on what the term means. Some have defined it as a social unit, which is generated by natural economic competition and selection (Frisbie, 1988). To others neighbourhood is a group of social network (Wellman, 1979). Whatever meaning is attached to neighbourhood, the fact is that it impacts significantly on a person's behaviour. Theories of neighbourhood influences as proposed by Shaw and McKay (1969), Wilson (1987), and Coleman (1988) clearly demonstrated the overwhelming influence of neighbourhood on the entire gamut of adolescent behaviour. These influences are brought about through mediating paths such as local organisations, informal social control, residents' consensus on conventional norms, deviant peer groups, helping social network and parents' characteristics. Previous studies on the influence of neighbourhood on adolescent alcohol use have demonstrated inconsistencies in their finding (Case, 1991; Karvonen and Rimpela, 1997; Allison, 1999). Some studies have found strong connection between neighbourhood influence and substance use. Crum (1996) for instance showed that residing in a disadvantaged neighbourhood increased the likelihood that adolescents were offered various kinds of substances (alcohol inclusive) and developed heavy drinking patterns (Karvonen, 1997). In other studies, neighbourhoods were found to have small effects compared with peer substance use (Abdelrahaman et al., 1998) or were found to have no effect at all on adolescent alcohol use (Allison, 1999). 
The purposes of the present study were to examine the combine and relative effect of peers, parents and neighbourhood influences on adolescent alcohol use. To achieve these objectives, the following research questions were posed and answered in the study.

\section{Research Questions}

(1) What was the joint effect of peer, parents and neighbourhood influences on adolescent alcohol use?

(2) What was the separate effect of peer, parents and neighbourhood influences on adolescent alcohol use.

\section{METHODOLOGY}

Research Design: The study is an ex-postfactor research design. It is an after-fact study which does not involve the manipulation of any variable. The paramount thing was to ascertain the effect of the independent variables (peers, parents, and neighbourhood) on the dependent variable (adolescent alcohol use) without manipulating either of them.

Participants: The participants in the study were five hundred secondary school students randomly drawn from twenty secondary schools in Oyo State, Nigeria. They were all in the senior secondary school classes one to three and their ranged between 13 and twenty years with a mean age of 15.9 years and standard deviation of 2.23. Three hundred and fifty of them are males and the rest are females.

Instrumentation: A questionnaire tagged 'Influences on Adolescent Alcohol Use Evaluative Questionnaire' (IAAUEQ) was constructed by the researcher. The questionnaire has three sections. namely: peer influence: parental influence and neighbourhood influence. The peer influence subscale has five items. a typical item on the

Table 1: Regression analysis on alcohol use data

\begin{tabular}{lll}
\hline Multiple R & $=$ & 424 \\
R Square & $=$ & .179 \\
Adjusted R-Square & $=$ & .165 \\
Standard Error & $=$ & 6.94
\end{tabular}

Analysis of Variance

\begin{tabular}{lrrrrr}
\hline Source & DF & $S S$ & $M S$ & F-Ratio & $P$ \\
\hline Regression & 3 & 2560.627 & 640.157 & 13.311 & $<0.05$ \\
Residual & 496 & 1782.28 & 48.0909 & & \\
\hline Total & 499 & $43,426,298$ & & & \\
\hline
\end{tabular}

subscale reads thus: taking alcohol is good since my friends take it'. The parental influence subscale has five items. An example of the items included here reads: 'I took alcohol because my parents also took it'. The neighbourhood influence subscale also has five items. A typical item of the subscale reads as follow: 'Our neighbours often send me to buy them alcohol'. The response formats for the items ranges from 'least like me (1)

The peer influence subscale has a reliability index of 0.81 ; the parental influence subscale has a reliability coefficient of 0.79 and the neighbourhood influence has a reliability index of 0.83 . The reliability of the instrument was determined through a test-retest method over an interval of three weeks.

Alcohol Consumption Rate Questionnaire (ACRQ): This instrument was developed by Adedokun (1991). It was designed to measure the rate of alcohol consumption. It is a twenty items scale with response format ranging from highly correct (5) to highly uncorrected (1). A typical item on the scale reads as follows: 'I take alcohol everyday'. The instrument has a testretest reliability index of 0.54 and a co-efficient alpha of 0.755 . The theoretical value of the scale range between 20 and 60 .

Procedure: The instruments were administered on the participants in their various schools by the researcher with the support of the school. Guidance and Counsellor.

Data Analysis: Multiple regression analysis was used to determine the combine and relative effects of the independent variables on the dependent variable.

\section{RESULTS}

\section{Research Question 1}

The result presented in Table 1 provided answer to the first research question which is interested in knowing the combine effect of the independent variables on the dependent. The result shows that the three independent variables when put together account for $16.5 \%$ of the variance in alcohol use among adolescents. to most like me (5). 
Table 2: Relative contributions of the independent variables to the prediction of alcohol use among the participants

\begin{tabular}{lrrrrrr}
\hline Variable Description & \multicolumn{2}{c}{ Unstandardized Coefficient } & & \multicolumn{3}{c}{ Standardized Coefficient } \\
\cline { 2 - 3 } \cline { 5 - 6 } & $B$ & Standard Error & & Beta & $t$ & $p$ \\
\hline Peer Influence & 0.32291 & 0.09712 & 0.2743 & 3.33 & $<0.05$ \\
Neighbourhood Influence & 208929 & 0.08904 & & 0.14265 & 2.36 & $<0.05$ \\
Parental Influence & 0.18867 & 0.098092 & 0.24 & 1.97 & $<0.05$ \\
\hline Source & $D F$ & $S S$ & $M S$ & $F$-Ratio & $P$ \\
\hline Regression & 3 & 2560.627 & 640.157 & 13.311 & $<0.05$ \\
Residual & 496 & 1782.28 & 48.0909 & & & \\
\hline Total & 499 & $43,426,298$ & & & \\
\hline
\end{tabular}

\section{Research Question 2}

Results on Table 2 show the regression coefficient (unstandardized and standardised, standard error of estimate, $\mathrm{t}$-ratio and the probability level at which t-ratios are significant.

\section{DISCUSSION}

The result of the first research question indicate that the three independent variables (peer, neighbourhood and parental influences) when combined together appeared to be effective in predicting alcohol consumption among the participants. The calculated F-value of 13.31 which is significant at 0.05 Alpha level further indicate that the capacity of the independent variables to predict alcohol consumption among adolescents could not have happened by chance.

As for the relative contribution of each of the variables, the results show that each of the independent variable made significant contribution to the prediction of alcohol use among the participants. The contribution of each of the variable in order of merit are: peer influence ( $=$ $.27430 ; \mathrm{t}=3.33 ; \mathrm{P}<0.05)$; neighbourhood influence $(\sim=.142645 ; \mathrm{t}=2-36 ; \mathrm{p}<0.05)$ and parental influence $(\sim=.239996 ; \mathrm{t}=1.97 ; \mathrm{p}<0.05)$.

The present finding has the support of those of Combs et al. (1991); Curran et al. (1997); Farell et al. (1992) and Mason and Windle (2002). These researches have provided evidences that social influences such as family drug use, peer drug use and neighbourhood alcohol use are critical antecedents of alcohol consumption among adolescents. The explanation for the present finding could be attributed to the fact that the independent variables in the study are proximal predictors of alcohol use among the participants. Again, these variables (peer, parental and neighbourhood influences) provide good drinking models to adolescents.

The finding that peer influence is the most potent predictor of alcohol use among the participants could be understood from the fact that adolescents are easily susceptible to peer pressure, peer encouragement and attitude (Ellickson, 1992). Parents wield enormous influence on their children and in fact they wield primary influence on them. When therefore, parents are into alcohol, they become drinking models to their adolescent children. Parents' life styles have vicarious effect on their children. Thus adolescent drinking behaviour can be a product of parental modelling. This opinion was shared by Wood et al. (2004) who noted that parents still matter in adolescents' choices about drinking.

Another variable that made significant contribution to the prediction of alcohol use was neighbourhood influence. This finding has the support of McKay (1969) Wilson (1987) and Coleman (1988). The predictive effect of neighbourhood influence may have been brought about through the channels of local organization, information, social control, residents' consensus on conventional norms, peer delinquency group, helping social networks and parents' characteristics. Again the participants in this study may have been influenced in their drinking habit as a result of residing in a disadvantaged neighbourhood. This explanation concurred with that of Crum (1996) who opined that living in such an environment may predispose adolescent to the likelihood of being offered various kinds of substances among which could be alcohol and consequently developed heavy drinking patterns (Carvonen, 1997).

\section{IMPLICATION OF THE FINDINGS}

Adolescents needed to be helped if they are 
to overcome their drinking problem. Counselling intervention such as self-monitoring, peer pressure management, self-regulation, values clarification, and thought stopping could help adolescents to withstand parental, neighbourhood and peer pressure all of which are implicated in this study as causative factors in adolescent drinking. The primary focus of intervention has to be the adolescents since it might not be possible to extend such intervention to those agents that predispose such adolescents to alcohol drinking. Community rehabilitation counselling centres would need to be established where they do not exist and further equipped and empowered where they are available. Realizing that majority of adolescents are in schools, there is need to strengthened the provision of counselling services in schools, hospitals and rehabilitation centres to minister unto the counselling needs of adolescents alcoholics.

\section{REFERENCES}

Abdelrahaman, A.I., Rodriguez, G., Ryan, J. French, F. and Wembaum, D.: The epidemiology of substance use among middle school student: The impact of school, familial community and individual risk factors. Journal of Child and Adolescents_Substances Abuse, 8(1): 55-75 (1998).

Adedokun, R.A.: Covert Sensitization and Self-Control Techniques in the Treatment of Alcoholism. unpublished Ph.D. thesis, University of Ibadan, Ibadan (1991).

Allison, K.W., Isaiah, C., Peter, E.L., Edson, T., Ahna, P. Reel, L.B. and Linda, M.B.: Adolescent's substance use. Preliminary examination of school and neighbourhood context. American Journal of Community Psychology, 27(2): 11-41 (1999).

Brook, J.S., Brook, D.W., Gordon, A. and Whiteman, M.: The psychosocial etiology of adolescent drug use. A family interactive approach. Genetic, Social and General Psychology Monograph, 116: 111267 (1990).

Case, A.C.: The company you keep: The effect of family and neighbourhood on disadvantaged youth Cambridge, M.A. National Bureau of Economic Research Notes: Working Paper, 1705 (1991).

Coleman, J.S.: Social capital in the creation of human capital. American Journal of Sociology, 94: S95S120 (1988).

Combs, R.H., Paulson, M.J. and Richardson, M.A.: Peer Vs Parental Influence in substance use among Hispanic and Anglo children and adolescents. Journal of Youth and Adolescence, 20: 73-88 (1991).

Cram, R.M., Marchal, L. and James, C.A.: Neighbourhood environment and opportunity to use cocaine and drugs in late childhood and early adolescence. Drug and Alcohol Dependence, 43: 155-161 (1996).

Curran, P.J., Stice, E. and Chasin, L.: The relation between adolescent alcohol use and peer alcohol use: A longitudinal random coefficient model. Journal of Consulting and Clinical Psychology, 65: 130-140 (1997).

Dupre, D., Miller, N., Gold, M. and Rospenda, K.: Initiation and progression of alcohol among adolescent abusers. American Journal of Addiction, 4(1): 43-48 (1995).

Eastang, V.G.: Call to drinkless alcohol. Weekly Star Paper, Sunday P. 2 (1990).

Ellickson, P.L. and Hays, R.D.: On becoming involved with drugs. Modelling adolescent drug use over time. Health Psychology, 11: 377-385 (1992).

Ethen, T.A.: A Survey of Teenage Perception of Parental Influence on Alcohol Consumption. Unpublished M.Sc. dissertation, University of Wisconsin (2000).

Farrell, A.D. and White, W.: Peer influences and drug use among urban adolescents: family structure and parents - adolescent relationship as protective factors. Journal of Consulting and Clinical Psychology, 66: 248-258 (1998).

Frisbie, W.P.: Spatial processes. (731-782). In: Handbook of Sociology. N.J. Smelser (Ed.). Sage Publication, Newbery Park: C.A. (1988).

Hanzelden Foundation: Alcoholism and Drug Abuse Weekly. (Masterfile Premier Document ReProduction Service No. AN. 681275 (1998).

Hoffmann, J.P.: Exploring the direct and indirect family effects on adolescent drug use. The Journal of Drug Issue, 23(3): $535-557$ (1993).

Jayant, K., Notani, PN., Gulati, S.S. and Gadre, V.V.: Alcohol usage in school children. Indian Journal of Cancer, 28(32): 139-147 (1991).

Jessor, R. and Jessor, S.L.: Adolescent development and the onset of drinking. Journal of Study on Alcohol, 36: 27-51 (1975).

Karvonen, S. and Harja, H.R.: Urban small area variation in adolescents health behaviour. Social Science Medicine, 45(7): 1089-1098 (1997).

Lindberg, D.L.; Burgress, S. and William, S.: Multiple Threats: The Co-Occurrence of Teen Health Risk Behaviour. Table 5. The Urban Institute, Washington, DC (2000).

Lowman, C.: Parental DimensioniIn Teenage Drinking. World Summer Publishing, New York (1982).

Martin, C.M. and Hoffman, M.A.: Alcohol expectation, living environment peer influence and gender: A model of college student drinking. Journal of College Student Development, 34: 206-211 (1993).

Mason, W.A. and Windle, M.: The Family, religious, school and peer influences on adolescent alcohol use. The Prevention Researcher, 9(3): 6-7 (2002).

McPherson, A. Diary of Teenage Health. Oxford University Press, London (1992).

Nash, J. Alcohol drinking style in school. Journal of Health Education, 46(4): 152-155 (1997).

National Institute of Alcohol Abuse and Alcoholism: Youth drinking: Risk factors and consequences Alcohol Alert, No. 37 (1997).

National Youth Violence Prevention: Facts for teens: Teens and Alcohol, Retrieved from www.safeyouth. org on 3/10/2005 (2000).

Ogunremi, O.O. and Rotimi, D.O.: The Nigerian Teenager and the use of drug. African Journal of Psychiatry, 1(2): 21-29 (1989).

Orcult, J.D.: The social integration of beers and peers: situational contingencies in drinking and intoxi- 
cation. pp. 198-215 In: Society, Culture and Drinking Patterns Reexamined. D. J. Pitman and H.R. White (Eds.). New Brondwick, NJ Rutgers Centre of Alcohol Studies (1991).

Permanent, K.: Alcohol in Human Violence. Guilford Press, New York (1991).

Roizen, J.: Epidemiological issues in alcohol-related violence. Pp. 7-40. In: Recent Development in Alcoholism. Vol. 13. M. Galanter (Ed.). Plenum Press, New York (1992).

Schwarzer, R.: Psychosocial correlates of substance use. Journal of Drug Education, 27: 545-549 (1997).

Shaw, C.R. and McKay, H.R.D.: Juvenile Delinquency and Urban Areas: A Study of Rates of Delinquency in Relation to Differential Characteristics of Local Communities in American Cities. The University of Chicago Press, Chicago (1969).

Swaim, O., Beauvais, I., Chavez, C. and Oetting, I. Patterns of adolescent substance use. Journal of Adolescents, 13(2): 105-108 (1997).

Van Hecke, M.A.: Teenagers and drinking: What are parents to do? Single Parents, 16: 35-38 (1995).

Wellman, B.: The community question: The intimate question of East workers. American Journal of Sociology, 84(5): 1201-1231 (1979).

Wilson, W.I. The Truly Disadvantaged: The Inner City, the Underclass and Public Policy. The University of Chicago Press, Chicago (1987). 